\title{
Complications of tracheal intubation in critically ill pediatric cancer patients
}

\author{
Suhail Sarwar Siddiqui, S. Janarthanan, M. M. Harish, Harish Chaudhari, R. Natesh Prabu, \\ Jigeeshu V. Divatia1, Atul Prabhakar Kulkarni
}

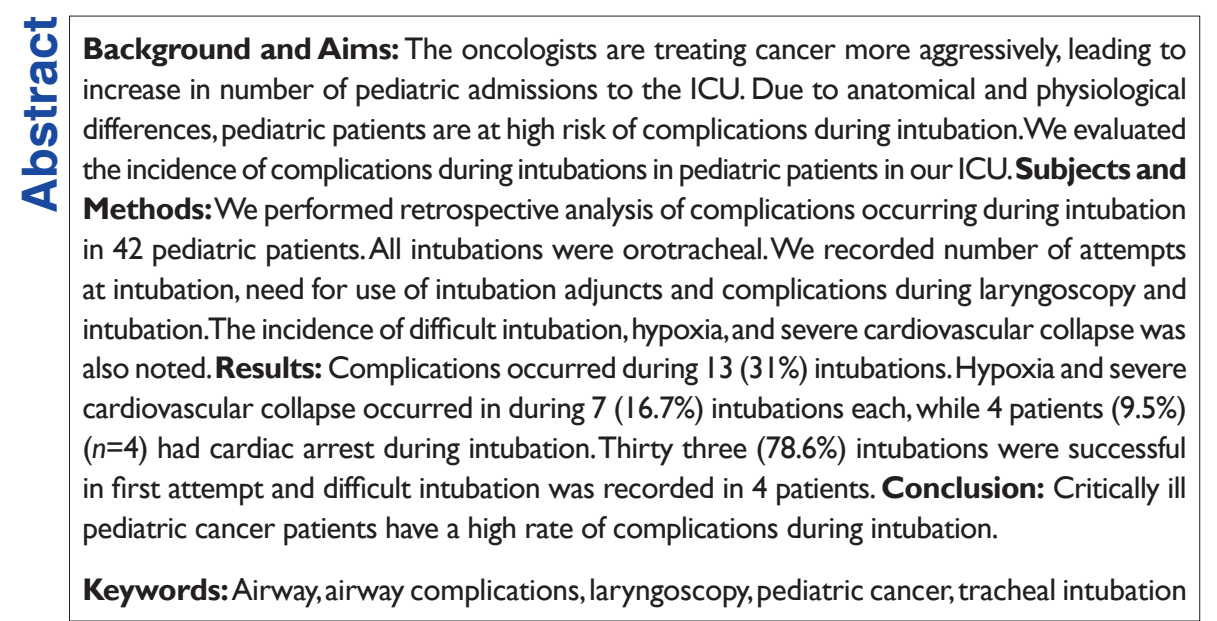

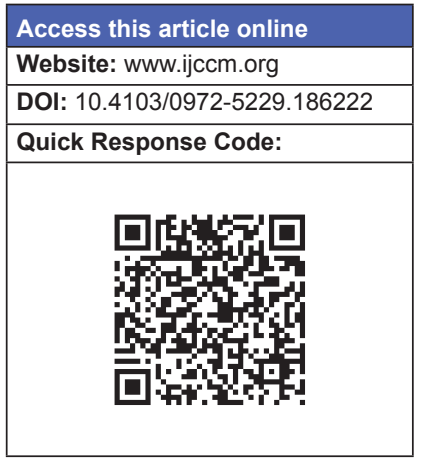

\section{Introduction}

Endotracheal intubation and mechanical ventilation is one of the mainstays in the management of critically ill patients. During intubation, several complications can occur ranging from dental trauma to cardiac arrest. ${ }^{[1-5]}$ Due to various anatomical and physiological differences compared to adults, intubation in pediatric patients is known to be difficult. Hence, they comprise population "at risk" of complications, which is compounded by critical illness and presence of underlying diseases.

Cancer is the second most common cause of death in children aged between 1 and 15 years throughout the world. ${ }^{[6]}$ Worldwide, the yearly number of new cases of childhood cancer exceeds 200,000 , of which more

From:

Department of Anaesthesia, Critical Care and Pain, Division of Critical Care Medicine, Tata Memorial Hospital, 'Department of Anaesthesia, Critical Care and Pain, Tata Memorial Hospital, Parel, Mumbai, Maharashtra, India

\section{Correspondence:}

Dr. Atul Prabhakar Kulkarni, Department of Anaesthesia, Critical Care and Pain, Division of Critical Care, Tata Memorial Hospital, Dr. E. Borges Road, Parel, Mumbai - 400 012, Maharashtra, India.

E-mail: kaivalyaak@yahoo.co.in than $80 \%$ occur in resource-challenged countries. ${ }^{[7]}$ The evolution in the field of oncology, both in diagnostic and therapeutic domains, has changed cancer from a terminal illness to a chronic disease. ${ }^{[8]}$ In future, increasing number of children with cancer will be admitted to the Intensive Care Units (ICUs), either for care of cancer-related symptoms or management of treatment-related complications.

Cancer among pediatric patients is not an uncommon entity, with prevalence rate from $4.2 \%$ to $21 \%$ of pediatric ICU or emergency department admissions. ${ }^{[9-12]}$ Recent data suggests that up to $38 \%$ of the pediatric oncology patients require ICU admission within 3 years of

This is an open access article distributed under the terms of the Creative Commons Attribution-NonCommercial-ShareAlike 3.0 License, which allows others to remix, tweak, and build upon the work non-commercially, as long as the author is credited and the new creations are licensed under the identical terms.

For reprints contact: reprints@medknow.com

How to cite this article: Siddiqui SS, Janarthanan S, Harish MM, Chaudhari H, Prabu RN, Divatia JV, Kulkarni AP. Complications of tracheal intubation in critically ill pediatric cancer patients. Indian J Crit Care Med 2016;20:409-11. 
diagnosis. ${ }^{[9]}$ There is plenty of literature available on the complications of intubation in general pediatric ICU patients, however studies pertaining to pediatric cancer patients are lacking. A study performed in the pediatric emergency department by Sukys et al. found that the frequency of success of intubation in cancer patients was lower than in patients without cancer. ${ }^{[12]}$ Hence, we decided to study the incidence of complications during intubation in pediatric cancer patients in our ICU.

\section{Materials and Methods}

Approval from the Institutional Ethics Committee was taken, and a waiver of informed consent was granted. The study was carried out in the ICU of a tertiary level cancer hospital. Our ICU caters to both adult and pediatric oncology patients, and annually, approximately 250 pediatric patients are admitted to our ICU. We did a retrospective analysis of prospectively collected data of 42 tracheal intubations performed in 39 pediatric patients from November 2013 to December 2014. Tracheal intubations were performed by senior residents who had at least 2 years of experience of intubation after their postgraduation, and they were supervised by consultant physicians. We excluded the intubations performed during cardiopulmonary resuscitation or those done immediately after unplanned extubation. Intubations performed in patients with mediastinal mass which caused tracheal compression or deviation as seen on computed tomography were not included in the study. We also excluded patients in whom intubation was performed using fiberoptic bronchoscope when difficult intubation was anticipated. We recorded complications during laryngoscopy and intubation, success rate at the first attempt, use of adjuncts such as bougie, stylet, and use of external manipulation such as backward, upward, and rightward pressure. Difficult intubation was defined as need for more than two attempts at laryngoscopy and intubation. Hypoxia was defined as fall of oxygen saturation to $<80 \%$ during laryngoscopy and intubation. Severe cardiovascular collapse was defined as hemodynamic instability needing vasopressor support or any increase in the dose of vasopressors. All patients received preoxygenation by either noninvasive ventilation or with AMBU bag with reservoir. Data were recorded in a case record form, which was reviewed by a dedicated fellow on a daily basis. In case of partially filled form or discrepancy in details, the person who did intubation was interviewed personally or on phone.

\section{Results}

The mean age of patients was $4.14 \pm 3.17$ years (range: 6 months to 12 years). Thirty-one of $42(73.8 \%)$ intubations were performed in male children. Twenty-five patients
(60\%) had hematolymphoid malignancies. The patient characteristics and age classification are shown in Table 1. Eight of 39 patients had either primary mediastinal or head and neck involvement. Of these, only five patients needed one attempt, two needed two attempts, and one needed four attempts. The most common reason for ICU admission was respiratory failure (74\%) followed by neurological problems $(21 \%)$ and shock $(5 \%)$. Induction agents and muscle relaxants were given as per discretion of the fellows on duty, and the most common induction agent and muscle relaxant used were ketamine and succinylcholine, respectively [Table 2]. Complications occurred during 13 (31\%) intubations. Hypoxia developed during seven (16.7\%) intubations, and severe cardiovascular collapse and cardiac arrest during intubation occurred in seven $(16.7 \%)$ and four (9.5\%) intubations, respectively. Other complications such as esophageal intubation, dangerous agitation, oral trauma, and aspiration of gastric content were less frequent [Table 3]. Total complications were more because some patients had more than one complication. Thirty-three $(78.6 \%)$ intubations were successful in the first attempt. Difficult intubation was encountered in four $(9.5 \%)$ patients. Only one patient required four attempts

\begin{tabular}{lc}
\hline Table I: Epidemiologic characteristics & \\
\hline Epidemiologic characteristics & $n(\%)$ \\
\hline Number of intubation encounters & 42 \\
Age range (mean age \pm SD) (years) & 6 months to I2 years \\
& $(4.14 \pm 3.17)$ \\
Age group distribution (years) & $7(18)$ \\
$<2$ & $20(5 I .3)$ \\
$2-4$ & $12(30.8)$ \\
$5-12$ & $31(73.8)$ \\
Males, $n(\%)$ & \\
Type of malignancies, $n$ (\%) & $25(59.5)$ \\
Hematolymphoid malignancies & $0(0)$ \\
With primary head and neck involvement & $1(2.4)$ \\
With primary mediastinal involvement & $17(40.5)$ \\
Solid organ & $3(7.1)$ \\
With primary head and neck involvement & $4(7.1)$ \\
With primary mediastinal involvement &
\end{tabular}

SD: Standard deviation

Table 2: Anesthetic drugs used during intubation

\begin{tabular}{lc}
\hline & $n(\%)$ \\
\hline Induction agents & \\
Ketamine & $3 \mathrm{I}(73.8)$ \\
Midazolam + fentanyl & $5(11.9)$ \\
Midazolam + morphine & $2(4.8)$ \\
Propofol & $3(7.1)$ \\
No induction agent & $\mathrm{I}(2.4)$ \\
Muscle relaxants & \\
Rocuronium & $7(16.7)$ \\
Succinylcholine & $3 \mathrm{I}(73.8)$ \\
Vecuronium & $\mathrm{I}(2.4)$ \\
No muscle relaxant & $3(7.1)$ \\
\hline
\end{tabular}




\section{Table 3: Complications during intubation}

\begin{tabular}{lc}
\hline Complications & $n(\%)$ \\
\hline Hypoxia & $7(I 6.7)$ \\
Severe cardiovascular collapse & $7(16.7)$ \\
Cardiac arrest - revived & $\mathrm{I}(2.4)$ \\
Cardiac arrest - died & $3(7.1)$ \\
Esophageal intubation & $\mathrm{I}(2.4)$ \\
Dangerous agitation & $\mathrm{I}(2.4)$ \\
Oral trauma & $\mathrm{I}(2.4)$ \\
Aspiration of gastric content & $\mathrm{I}(2.4)$ \\
\hline
\end{tabular}

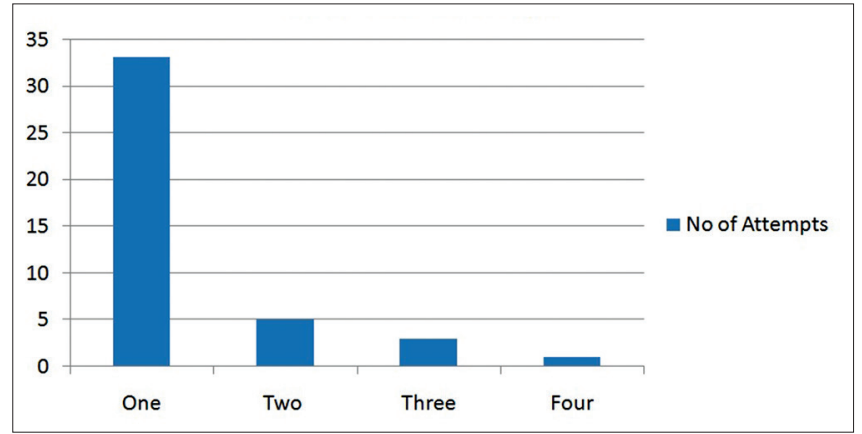

Figure I: Number of attempts

[Figure 1]. Adjuncts to intubation were used in seven $(16.7 \%)$ patients. No patient needed surgical airway.

\section{Discussion}

Rate of intubation-related complications in our study is higher $(31 \%)$ as compared to a recent study, which has reported complications in $19.3 \%$ of the intubations. ${ }^{[13]}$ This can be attributed to a sample configuration as all the patients in our study had underlying cancer. Sukys et al. reported a very high rate of complications (80\%), which is far higher than ours. ${ }^{[12]}$ However, in that study, second-year pediatric residents performed the majority of intubations (74\%) as opposed to our study, where in all the cases, there was constant presence of two operators at head end, one thirdyear anesthesia resident, and a 2 year post-M.D. fellow during the procedure. Success rates of our first attempt $(78.6 \%)$ were better than or comparable to the reported rates of other studies. ${ }^{[2,12,13]}$ We do have an institutional protocol for fiberoptic intubation; however, the fiberscope is not available after the operating theaters were closed. We are, however, in the process of acquiring a pediatric fiberscope for the ICU, which will then be available in the ICU round-the-clock.

Our rates of cardiac arrest (9.5\%) were quite high as compared to other studies. ${ }^{[2,12,13]}$ The high incidence of cardiac arrest may have been due to the presence of shock at the time of intubation. Of the four patients who had cardiac arrest, only one could be revived. The remaining three children were in shock and were on high doses of vasopressors at the time of intubation. Of these three, one also had pulmonary bleeding with refractory hypoxemia before intubation. In a study by Schwartz et al., hypotension was found to be a strong predictor of cardiac arrest and mortality. ${ }^{[14]}$ In view of large number of complications, we suggest that the residents should be trained using simulator-based programs, particularly when the unit is dealing with a large number of pediatric cancer patients. The limitations of our study are that it is a single-center study and includes a small number of patients.

We conclude that pediatric patients with underlying cancer may have higher rate of complications during intubation, and these appear to be more severe as compared to general pediatric ICU patients.

\section{Financial support and sponsorship \\ Nil.}

\section{Conflicts of interest}

There are no conflicts of interest.

\section{References}

1. Divatia JV, Bhowmick K. Complications of endotracheal intubation and other airway management procedures. Indian J Anaesth 2005;49:308-18.

2. Sanders RC Jr., Giuliano JS Jr., Sullivan JE, Brown CA $3^{\text {rd }}$, Walls RM, Nadkarni V, et al. Level of trainee and tracheal intubation outcomes. Pediatrics 2013;131:e821-8.

3. Souza ND, Carvalho WB. Complications of tracheal intubation in pediatrics. Rev Assoc Med Bras 2009;55:646-50.

4. Mort TC. The incidence and risk factors for cardiac arrest during emergency tracheal intubation: A justification for incorporating the ASA Guidelines in the remote location. J Clin Anesth 2004;16:508-16.

5. Simpson GD, Ross MJ, McKeown DW, Ray DC. Tracheal intubation in the critically ill: A multi-centre national study of practice and complications. Br J Anaesth 2012;108:792-9.

6. Sapolnik R. Intensive care therapy for cancer patients. J Pediatr (Rio J) 2003;79 Suppl 2:S231-42.

7. Arora RS, Eden TO, Kapoor G. Epidemiology of childhood cancer in India. Indian J Cancer 2009;46:264-73.

8. von Bergwelt-Baildon M, Hallek MJ, Shimabukuro-Vornhagen AA, Kochanek M. CCC meets ICU: redefining the role of critical care of cancer patients. BMC Cancer 2010;10:612.

9. Zinter MS, DuBois SG, Spicer A, Matthay K, Sapru A. Pediatric cancer type predicts infection rate, need for critical care intervention, and mortality in the pediatric intensive care unit. Intensive Care Med 2014;40:1536-44.

10. El Halal MG, Barbieri E, Filho RM, Trotta Ede A, Carvalho PR. Admission source and mortality in a pediatric intensive care unit. Indian J Crit Care Med 2012;16:81-6.

11. Khositseth A, Anantasit N, Vaewpanich J. Deaths in a pediatric intensive care unit: A review over three years. Sri Lanka J Child Health 2012;41:166-70.

12. Sukys GA, Schvartsman C, Reis AG. Evaluation of rapid sequence intubation in the pediatric emergency department. J Pediatr (Rio J) 2011;87:343-9.

13. Nishisaki A, Ferry S, Colborn S, DeFalco C, Dominguez T, Brown CA $3^{\text {rd }}$, et al. Characterization of tracheal intubation process of care and safety outcomes in a tertiary pediatric intensive care unit. Pediatr Crit Care Med 2012;13:e5-10.

14. Schwartz DE, Matthay MA, Cohen NH. Death and other complications of emergency airway management in critically ill adults. A prospective investigation of 297 tracheal intubations. Anesthesiology 1995;82:367-76. 